\title{
RFLP analysis of 1-aminocyclopropane-1-carboxylate synthase ACC2 and ACC4 genes from Polish cultivars of tomato
}

\author{
Małgorzata Jakubowicz ${ }^{\bowtie}$, Justyna Jółkowska, Grażyna Kwapiszewska, Anna Kręcisz \\ and Piotr Czerski
}

Institute of Molecular Biology and Biotechnology, Adam Mickiewicz University, Międzychodzka 5, 60-371 Poznań, Poland

Received: 15 March, 2002; revised: 18 June, 2002; accepted 12 November, 2002

Key word: 1-aminocyclopropane-1-carboxylate synthase

\begin{abstract}
An important trait of tomato is the rate of fruit ripening, strongly dependent on ethylene production. The ripening-related ethylene synthesis in tomato is controlled mainly by 1-aminocyclopropane-1-carboxylate synthase LE-ACS2 and LE-ACS4 isoenzymes (Rottmann et al., 1991, J. Mol. Biol. 222: 937; Lincoln et al., 1993, J. Biol. Chem. 268: 19422; Barry et al., 2000, Plant Physiol. 123: 979). In spite of numerous reports on the LE-ACS2 and LE-ACS4 gene expression, only ones considered the genomic organisation each of these genes (Rottmann et al., 1991; Lincoln et al., 1993) reported one copy of each of these genes in tomato cv VF36. In this article we suggest that the genomic organisation of LE-ACS2 and LE-ACSS4 genes may depend on tomato cultivars and may differ from that described by the above authors. The results of Southern analyses of genomic DNAs from 17-day old seedlings (cultivars Jaga, Halicz, Betalux, New Yorker) imply that the genomic organisation of LE-ACS2 and LE-ACS4 genes in Polish cultivars differs from that reported for cv VF36.
\end{abstract}

Ethylene controls many aspects of plant development. Enhanced rates of ethylene production are observed in response to biotic and abiotic stress and in climacteric plants during fruit ripening and flower senescence. Higher plants produce ethylene from $S$-adenosyl-L-methionine (SAM) via 1-aminocyclopropane-1-carboxylic acid (ACC). ACC synthase ( $S$-adenosyl-L-methionine methyl- thioadenosine-lyase, EC 4.4.1.14), the enzyme catalysing the conversion of SAM to ACC (the most important step in ethylene synthesis) is encoded by a highly divergent multigene family in a number of plant species (Huang et al., 1991; Rottmann et al., 1991; Liang et al., 1992; Botella et al., 1993; Lincoln et al., 1993; Destefano-Beltran et al., 1995; Subramanian et al., 1996; Oetiker et al., 1997; Zarembinsky

\footnotetext{
${ }^{凶}$ Author to whom correspondence should be addressed; e-mail goja@amu.edu.pl

Abbreviations: ACC, 1-amino-cyclopropane-1-carboxylic acid; ACS, 1-aminocyclopropane-1-carboxylate synthase; SAM, $S$-adenosyl-L-methionine.
} 
\& Theologis, 1997; Bui \& O’Neill, 1998; Shiu et al., 1998; Barry et al., 2000; Bekman et al., 2000; Ishiki et al., 2000). Enhanced ethylene synthesis is usually correlated with an elevated level of 1-aminocyclopropane-1-carboxylate synthase mRNA, but regulatory mechanisms at the posttranscriptional level are also involved.

In tomato, nine members of the LE-ACS multigene family have been reported (Rottmann et al., 1991; Lincoln et al., 1993; Oetiker et al., 1997; Shiu et al., 1998; EMBL GeneBank Database 2002). Three of these genes, LE-ACS1A, LE-ACS2 and LE-ACS4, show ripening-related increase in expression. The level of their transcripts is low or undetectable in mature green fruit and increases at the breaker stage (Barry et al., 2000). LE-ACS6 transcripts are present in mature green fruit but decline as ripening is initiated. When ripening is in progress, the levels of the most abudant ripening-related LE-ACS2 and LE-ACS4 transcripts continue to rise, and ethylene has an autostimulatory effect on their transcription. Both transcripts are superinduced by wounding of the pericarp tissue. Contrary to LE-ACS4 transcripts which are specific only for ripening fruit, LE-ACS2 trancripts have been found after pathogen attack, in flooded roots, in elicited tomato suspension culture, in mature and senescent anthers, and in fully senescent petals (Rottmann et al., 1991; Oetiker et al., 1997; Llop-Tous et al., 2000).

The chromosomal localisation of LE-ACS2 and $L E$-ACS4 genes was established for tomato derived from the interspecific cross Lycopersicon esculentum cv VF36-Tm2a x Lycoperscon pennelli LA716. The two species used in this cross have the same chromosome constitution $(2 \mathrm{n}=24)$, (Rottmann et al., 1991; Tanksley et al., 1992). LE-ACS2 gene resides on chromosome 1 and LE-ACS4 gene on chromosome 5. The copy number described for cultivar VF36 for each of these two genes was one per a haploid genome (Rottmann et al., 1991; Lincoln et al., 1993).
Such an essential trait of tomato as the rate of fruit ripening is developmentally regulated and strongly depends on LE-ACS2 and LE-ACS4 gene expression. We therefore decided to investigate the LE-ACS2 and $L E$-ACS4 gene organisation in tomato cultivated in Poland.

\section{MATERIALS AND METHODS}

Plant material. We used the following cultivars of tomato: Jaga, Halicz and Betalux - cultivars brought up in Poland; New Yorker - cultivar brought up in the U.S.A. from crosses: (Geneva11 x Rhode Island) x Fireball. The New Yorker has been imported to Poland thirty years ago and since then cultivated and improved by breeders. All of these cultivars differ from each other in morphology. Results of the RAPD analysis have confirmed also some genetic differences between these cultivars (unpublished results). The plants used for Southern analysis were grown in pots as 17-day old seedling under $16 \mathrm{~h}$ daylight and at $25^{\circ} \mathrm{C}$.

DNA isolation. DNA extraction from young seedlings was performed according to the method of Junghans \& Metzlaff (1990). DNA concentration was measured spectrophotometrically at $260 \mathrm{~nm}$.

Southern analysis of genomic DNA. Approximately $10 \mu \mathrm{g}$ of total genomic DNA was digested with a tenfold excess of restriction enzyme in a buffer supplied by the enzyme manufacturer (Fermentas) and following electrophoresis in $0.8 \%$ agarose gel, transferred to Hybond-N Plus membranes (Amersham).

Gene-specific 3'probe for LE-ACS2 represented the last exon of the gene from nucleotides 534 through 1553 (according to cDNA GenBank X59145). It was PCR-generated using $\mathrm{T} 1$ and $\mathrm{T} 2$ primers and total DNA cv Jaga. The PCR amplified fragment was cloned and sequenced to confirm its authenticity. Gene-specific 3 ' probe for LE-ACS4 was a PCR amplified fragment representing the last 
exon of the gene. The 3 ' probe from nucleotides 528 through 1444 (according to cDNA GenBank X59146) was generated using AS1 and AS2 primers and total DNA cv Betalux. The amplified fragment of LE-ACS4 was cloned and sequenced before using it as a hybridisation probe to confirm its authenticity. Hybridisation and washes were carried out at high stringency according to Amersham protocols for Hybond-N nylon membrane. The probe was labelled by the random hexamer priming method using the Promega system. Sequencing was performed using the f-mol sequencing kit from Promega.

Primers. PCR primers used for the analysis were designed from sequences deposited within databases.

T1, 5' gggaattcactaatgcAGATTTAACAGAG $3^{\prime}$ (562), small letters - nucleotides complementary to the part intron 3, capital letters to the sequence of exon 4; numbering according to cDNA (GenBank X59145).

T2, 5' (1553) AAGTCTAGACGAGCTCATGGTGAGGGAGG 3' (1525)

AS1, 5' (528) ATTTAATAGGGACCTAAGGTGG 3' (549)

AS2, 5' (1462) ACATTTTCATCGTACTCCCCATTTG 3' (1444)

The PCR conditions were: predenaturation step at $95^{\circ} \mathrm{C}, 4 \mathrm{~min}$, followed by 5 cycles, each consisting of a denaturation step of $1 \mathrm{~min}$ at $94^{\circ} \mathrm{C}$, an annealing step of $2 \mathrm{~min}$ at $55^{\circ} \mathrm{C}$ and extension of $2 \mathrm{~min}$ at $72^{\circ} \mathrm{C}$; the next 35 cycles were: $1 \mathrm{~min}$ at $94^{\circ} \mathrm{C}, 2 \mathrm{~min}$ at $57^{\circ} \mathrm{C}$ and $2 \mathrm{~min}$ at $72^{\circ} \mathrm{C}$.

\section{RESULTS AND DISCUSSION}

LE-ACS2 gene expression has been investigated by many authors but its organisation was reported only by Rottmann et al. (1991), who analysed five overlapping EMBL-lambda genomic clones containing the LE-ACS2 gene and the flanking regions.

LE-ACS4 gene expression has been characterized by several authors but the organisa- tion of the gene was reported by one research group only for cultivar VF36. Rottmann et al. (1991) and Lincoln et al. (1993) investigated the $17 \mathrm{~kb}$ fragment of the tomato nuclear DNA from EMBL-3-lambda clone containing $L E$ ACS4 gene and the total genomic DNA from cultivar VF36.

\section{Genomic Southern analysis of $L E$-ACS2 gene organisation}

The Southern analysis was performed for the total genomic DNA from 17-day old seedlings. The 3 ' probe was a PCR-generated fragment corresponding to the last exon of the LE-ACS2 gene which contained about $70 \%$ of the coding region. The restriction fragments hybridising with the 3 ' probe were identical for all cultivars analysed (Fig. 1). There were five EcoRI strongly hybridising fragments: $1.7 \mathrm{~kb} ; 2.5 \mathrm{~kb} ; 2.7 \mathrm{~kb} ; 3.2 \mathrm{~kb}$ and $3.6 \mathrm{~kb}$ and $\mathrm{a}$ few weakly hybridising fragments. There was one strongly hybridising $4.2 \mathrm{~kb}$ HindIII fragment and a few weakly hybridising fragments smaller than $4.2 \mathrm{~kb}$. The 3 ' probe hybridised with the high molecular mass fragments greater than $10 \mathrm{~kb}$ in the case EcoRI and HindIII digested DNA, probably because of the presence of the highly methylated undigested genomic DNA.

In summary, our results do not correspond strictly to the LE-ACS2 gene organisation reported by Rottmann et al. (1991), and may suggest a polymorphic character of LE-ACS2 genes or more than one copy of LE-ACS2 in the analysed tomato cultivars.

\section{Genomic Southern analysis of $L E-A C S 4$ organisation}

Southern analysis was performed for the total genomic DNA from 17-day old seedlings of different cultivars (Jaga, Halicz, Betalux, New Yorker). We used the same EcoRI and HindIII digested DNAs which were used in LE-ACS2 analysis. The hybridisation 3 ' probe was a PCR-generated fragment representing the 
17-day old seedlings

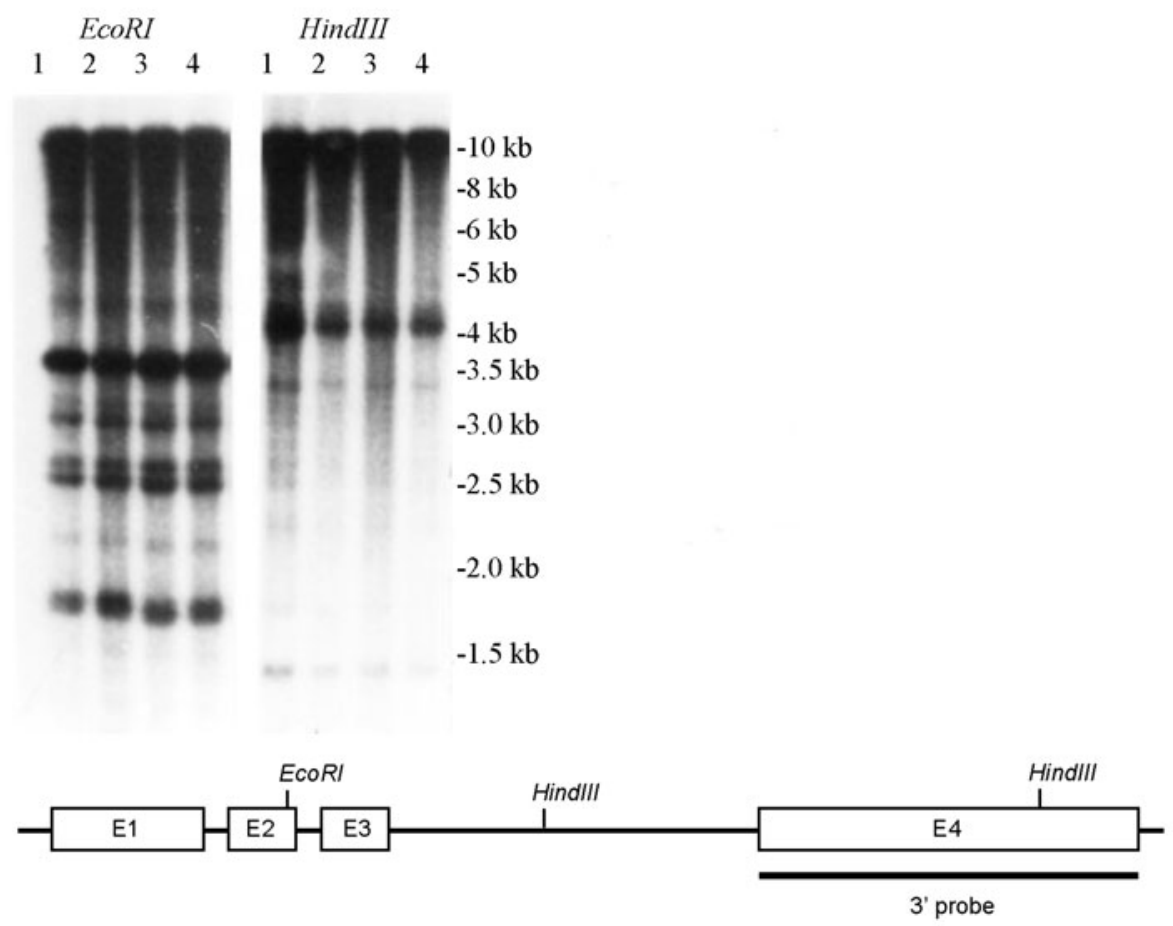

Figure 1. Southern analysis of DNA isolated from 17-day old seedlings.

Tomato genomic DNA from cultivars Jaga (1), Halicz (2), Betalux (3) and New Yorker (4) were digested with EcoRI and HindIII. The $3^{\prime}$ probe was the ${ }^{32}$ P-labelled fragment representing the fourth exon of the LE-ACS2 gene. LE-ACS2 organisation and the partial restriction map (E, H - EcoRI and HindIII, respectively) was shown according to Rottmann et al. (1991). Each lane contains $10 \mu \mathrm{g}$ of digested genomic DNA. The size markers shown on the right is the $1 \mathrm{~kb}$ DNA ladder (Fermentas).

last exon of LE-ACS4 gene which contained about $70 \%$ of the coding region. The 3 ' probe strongly hybridised with $4.0 \mathrm{~kb}$ and $5.0 \mathrm{~kb}$ and weakly with $2.25 \mathrm{~kb}$ and $2.5 \mathrm{~kb}$ HindIII fragments and with the single $1 \mathrm{~kb}$ EcoRI fragment (Fig. 2).

The results of Southern analysis of $L E$ ACS4 gene were the same for all cultivars analysed but different from those published by Lincoln et al. (1993) for cultivar VF36.

\section{Sequence analysis of the last exon of \\ LE-ACS4 gene from the cultivar Betalux}

Rottmann et al. (1991) reported that the cloned LE-ACS4 gene from cv VF36 and $L E$-ACS4 cDNA from ripening tomato of a unknown cultivar differed at eight positions. We have cloned PCR-generated fragments corresponding to the last exon of LE-ACS4 gene from cultivar Betalux. The region of LE-ACS4 from $550 \mathrm{nt}$ to $982 \mathrm{nt}$ of each clone was sequenced (numbering according to LE-ACS4 cDNA GenBank/EMBL Data Bank accession number X59146). The nucleotide sequence of the last exon of LE-ACS4 gene from among the seven Betalux clones analysed was consistent with the published LE-ACS4 cDNA sequence from an unknown cultivar of tomato at the four controversial positions of this region (LE-ACS4 cDNA and Betalux LE-ACS4 gene $\mathrm{T}_{741}, \mathrm{~A}_{798}, \mathrm{C}_{805}, \mathrm{G}_{936}$; numbering according to cDNA). This strongly suggests that the form of the LE-ACS4 gene from cv VF36 reported by Rottmann et al. (1991) and by Lincoln et al. (1993) does not occur in cultivar Betalux and probably also in the other cultivars analysed. The nucleotide sequence of $L E$-ACS4 gene found in cultivar Betalux is the same at the controversial positions as that 


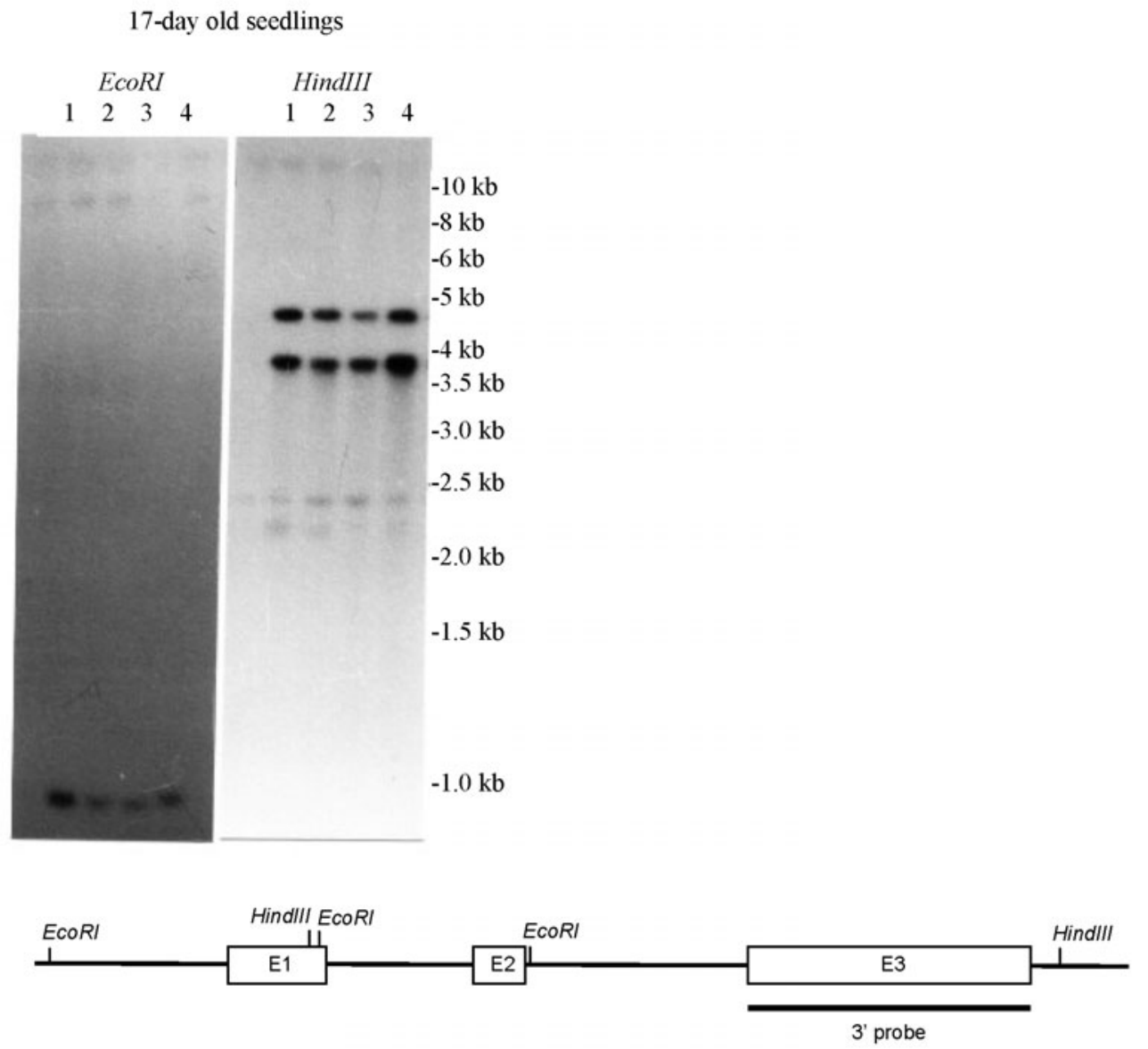

Figure 2. Southern analysis of DNA isolated from 17-day old seedlings.

The $3^{\prime}$ probe was the ${ }^{32}$ P-labelled fragment representing the last exon of the LE-ACS4 gene. LE-ASC4 organisation and the partial restriction map was shown according to Lincoln et al. (1993). Each lane contains $10 \mu \mathrm{g}$ of digested genomic DNA. All designations and the size markers as in Fig 1.

in the reported LE-ACS4 cDNA sequence. This result may suggest that the transcriptionally active form of the whole LE-ACS4 gene has not been characterised till now.

The breeders interest is to generate the quality features associated with the growth and ripening of tomato fruits. Probably, the reported organisation and copy number of $L E$-ACS2 and $L E$-ACS4 genes is best adapted to the local climate requirements and was fixed in the genetic pool of tomato cultivars in Poland.

We thank late Professor Jacek Augustyniak for helpful discussions.

\section{R E F E R E N C E S}

Barry CS, Llop-Tous MI, Grierson D. (2000) The regulation of 1-aminocyclopropane-1-carboxylic acid synthase gene expression during the transition from system-1 to system-2 ethylene synthesis in tomato. Plant Physiol.; 123: $979-86$.

Bekman EP, Saibo NJM, Di Cataldo A, Regalado AP, Ricardo CP, Rodriques-Pousada C. (2000) Differential expression of four genes encoding 1-aminocyclopropane-1-carboxylate synthase in Lupinus albus during germination, and in response to indole-3-acetic acid and wounding. Planta.; 211: 663-72.

Botella JR, Schlagnhaufer CD, Arteca JM, Arteca RN, Phillips AT. (1993) Identification of two new members of the 1-aminocyclopropane-1-carboxylate synthase-encoding 
multigene family in mung bean. Gene.; 123: 249-53.

Bui AQ, O’Neill SD. (1998) Three 1-aminocyclopropane-1-carboxylate synthase genes regulated by primary and secondary pollination signals in orchid flowers. Plant Physiol.; 116: $419-28$.

Destefano-Beltran LJC, Van Caeneghem W, Gielen J, Richard L, Van Montagu M, Van Der Straeten D. (1995) Characterization of three members of the ACC synthase gene family in Solanum tuberosum. Mol Gen Genet.; 246: 496-508.

Huang PL, Parks JE, Rottmann WH, Theologis A. (1991) Two genes encoding 1-aminocyclopropane-1-carboxylate synthase in zucchini (Cucurbita pepo) are clustered and similar but differentially regulated. Proc Natl Acad Sci U S A.; 88: 7021-25.

Ishiki Y, Oda A, Yaegashi Y, Orihara Y, Arai T, Hirabashi T, Nakagawa H, Sato T. (2000) Cloning of an auxin-responsive 1-aminocyclopropane-1-carboxylate synthase gene from melon and expression of ACS genes in etiolated melon seedlings and melon fruits. Plant Sci.; 159: 173-81.

Junghans H, Metzlaff M. (1990) A simple and rapid method for the preparation of total plant DNA. BioTech.; 8: 176.

Liang X, Abel S, Keller JA, Shen NF, Theologis A. (1992) The 1-aminocyclopropane-1carboxylate synthase gene family of Arabidopsis thaliana. Proc Natl Acad Sci U S A.; 89: 11046-50.

Lincoln JE, Campbell AD, Oetiker J, Rottmann WH, Oeller PW, Shen NE, Theologis A. (1993) LE-ACS4, a fruit ripening and wound-induced 1-aminocyclopropane-1-carboxylate synthase gene of tomato (Lycopersicon esculentum). J Biol Chem.; 268: 19422-30.

Llop-Tous I, Barry CS, Grierson D. (2000) Regulation of ethylene biosynthesis in response to pollination in tomato flowers. Plant Physiol.; 123: 971-78.

Oetiker JH, Olson DC, Shiu OY, Yang SF. (1997) Differential induction of seven 1-aminocyclopropane-1-carboxylate synthase genes by elicitor in suspension cultures of tomato (Lycopersicon esculentum). Plant Mol Biol.; 34: 275-86.

Rottmann WH, Peter FG, Oeller PW, Keller JA, Shen NF, Nagy BP, Taylor LP, Campbell AD, Theologis A. (1991) 1-Aminocyclopropane-1-carboxylate synthase in tomato is encoded by a multigene family whose transcription is induced during fruit and floral senescence. J Mol Biol.; 222: 937-61.

Shiu OY, Oetiker JH, Yip WK, Yang SF. (1998) The promoter of LE-ACS7, an early flooding-induced 1-aminocyclopropane-1-carboxylate synthase gene of the tomato, is tagged by a Sol3 transposon. Proc Natl Acad Sci U S A.; 95: 10334-9.

Subramanian K, Abbo S, Ueng PP. (1996) Isolation of two differentially expressed wheat ACC synthase cDNA and characterization of one of their genes with root-predominant expression. Plant Mol Biol.; 31: 1009-20.

Tanksley SD, Ganal MW, Prince JP, de Vincente MC, Bonierbale MW, Broun P, Fulton TM, Giovannoni JJ, Grandillo S, Martin GB, Messeguer R, Miller JC, Paterson AH, Pineda O, Roder MS, Wing RA, Wu W, Young ND. (1992) High density molecular linkage maps of the tomato and potato genomes. Genetics.; 132: 1141-60.

Zarembinsky TI, Theologis A. (1997) Expression characteristics of OS-ACS1 and OS-ACS2, two members of the 1-aminocyclopropane-1-carboxylate synthase gene family in rice during partial submergence. Plant $\mathrm{Mol}$ Biol.; 33: 71-7. 